\title{
Isolation of Aspergillus niger creA mutants and effects of the mutations on expression of arabinases and L-arabinose catabolic enzymes
}

\author{
George J. G. Ruijter, Sipo A. Vanhanen, + Marco M. C. Gielkens, \\ Peter J. I. van de Vondervoort and Jaap Visser
}

Author for correspondence: Jaap Visser. Tel: +31 317 484439. Fax: +31 317484011.
e-mail: office@algemeen.mgim.wau.nl

Section Molecular Genetics of Industrial

Microorganisms,

Wageningen Agricultural

University, Dreijenlaan 2,

6703 HA Wageningen,

The Netherlands

\begin{abstract}
Aspergillus niger mutants relieved of carbon repression were isolated from an areA parental strain by selection of colonies that exhibited improved growth on a combination of 4-aminobutanoic acid (GABA) and D-glucose. In addition to derepression of the utilization of GABA as a nitrogen source in the presence of D-glucose, three of the four mutants also showed derepression of L-alanine and L-proline utilization. Transformation of the mutants with the A. niger creA gene, encoding the repressor protein CREA, re-established the areA phenotype on GABAD-glucose, identifying the mutations as creAd. The creA gene mapped on chromosome IV by linkage analysis and contour-clamped homogeneous electric field hybridization. The creA mutants obtained were used to study the involvement of CREA in repression by D-glucose of arabinases and L-arabinose catabolism in A. niger. In wild-type A. niger, $\alpha$-L-arabinofuranosidase A, $\alpha$-Larabinofuranosidase $B$, endo-arabinase, L-arabinose reductase and L-arabitol dehydrogenase were induced on L-arabinose, but addition of D-glucose prevented this induction. Repression was relieved to varying degrees in the creA mutants, showing that biosynthesis of arabinases and L-arabinose catabolic enzymes is under control of CREA.
\end{abstract}

Keywords: carbon repression, creA, L-arabinose, arabinase, Aspergillus niger

\section{INTRODUCTION}

Carbon repression is a global regulatory mechanism in which the presence of D-glucose or other rapidly metabolizable carbon sources represses expression of genes involved in the utilization of less-favoured carbon sources (for reviews on carbon repression in fungi see Ruijter \& Visser, 1997; Scazzocchio et al., 1995; Kelly, 1994). It allows micro-organisms to cope smoothly with changes in the carbon sources present in their environment. Genetic analysis has shown that carbon repression in Aspergillus nidulans is mediated by a major regulatory gene, $c r e A$, which acts in a negative manner (Arst \& MacDonald, 1975; Arst \& Bailey, 1977). Mutations in A. nidulans creA result in derepres-

\footnotetext{
†Present address: Department of Biological Sciences, University of Durham, South Road, Durham, DH1 3LE, UK.

Abbreviations: ABFA, $\alpha$-L-arabinofuranosidase A (EC 3.2.1.55); ABFB, $\alpha$ L-arabinofuranosidase B (EC 3.2.1.55); ABNA, endo-1,5- $\alpha$-L-arabinanase (EC 3.2.1.99); CHEF, contour-clamped homogeneous electric field; GABA, 4-aminobutanoic acid; PNP-A, $p$-nitrophenyl $\alpha$-L-arabinofuranoside.
}

sion of a variety of activities which are normally repressed by D-glucose (Arst \& Cove, 1973; Bailey \& Arst, 1975; Hynes \& Kelly, 1977). creA mutations were isolated by several strategies including selection of pseudorevertants of are $A$-defective strains. The creA gene has been cloned and sequenced from both $A$. nidulans (Dowzer \& Kelly, 1989, 1991) and Aspergillus niger (Drysdale et al., 1993) and has been shown to encode a DNA-binding protein containing two zinc fingers of the $\mathrm{Cys}_{2} \mathrm{His}_{2}$ type, which are very similar to the zinc fingers of MIG1, the repressor involved in glucose repression of the GAL and SUC2 genes in Saccharomyces cerevisiae (Nehlin \& Ronne, 1990; Nehlin et al., 1991).

Plant cell walls consist of complex polysaccharides of which L-arabinan is one of the constituents. Mycelial fungi are able to degrade these polysaccharides into monomeric sugars, which are subsequently metabolized further. The L-arabinan-degrading system of $A$. niger consists of two distinct $\alpha$-L-arabinofuranosidases (ABFs) (ABFA and ABFB) and an endo-1,5- $\alpha$-arabinanase (ABNA) (Van der Veen et al., 1991). The expression of 
these three enzymes is under the control of pathwayspecific induction and carbon repression. Three arabinase-encoding genes, $a b f A, a b f B$ and $a b n A$, have been cloned and characterized (Flipphi et al., 1993a, b, c, 1994). In the promoters of these three genes several putative CREA-binding sites, i.e. sequence elements identical to the $A$. nidulans CREA motif $5^{\prime}-\mathrm{G} / \mathrm{CPyG}$ GPuG-3' (Kulmburg et al., 1993; Cubero \& Scazzocchio, 1994) as well as some elements common to all arabinase genes can be found (Flipphi et al., 1994).

Although the $A$. niger creA gene has been cloned, the selection of $A$. niger cre $A$ mutants has thus far never been described. By conventional mutagenesis we have now isolated four $A$. niger cre $A$ mutants which are useful to establish whether various metabolic systems are under CREA control. As an example, we have studied L-arabinan degradation and L-arabinose catabolism.

\section{METHODS}

A. niger strains, isolation of mutants and linkage analysis. All strains used were descendants from A. niger N400 (CBS 120.49). N402 (cspA1) was used for contour-clamped homogeneous electric field (CHEF) analysis. NW141 (areA1 bioA1 cspA1 pyrA13) was isolated from NW140 (areA1 bioA1 cspA1; L. Fraissinet-Tachet \& J. Visser, unpublished). N616 (Bos et al., 1988) was used as a test strain for genetic analysis. UV-mutagenesis and isolation of pyrA mutants were performed as described by Goosen et al. (1987). The survival of the spores for the selection of the pyrA13 marker was more than $50 \%$. Selection of the creA mutants was done after UVmutagenesis, resulting in $38 \%$ survival. Irradiated conidia $\left(4.5 \times 10^{7}\right)$ of strain NW141 were plated on 10 minimal medium (MM) plates (see below) containing $1 \%(\mathrm{w} / \mathrm{v}) 4$ aminobutanoic acid (GABA) and $1 \%(w / v)$ D-glucose. After $4 \mathrm{~d}$ incubation at $30^{\circ} \mathrm{C}, 80$ colonies were picked and tested on various combinations of carbon and nitrogen sources.

Linkage analysis was performed as described by Bos et al. (1988). Test strain N616 contains genetic markers on six linkage groups: fwnA1 (I), hisD4 (II), lysA7 (III), leuA1 (IV), $n i c A 1(\mathrm{~V})$ and pabA1 (VI).

Medium and culture conditions. Mycelium was cultured on minimal medium (MM; Pontecorvo et al., 1953) containing $0.02 \%(\mathrm{v} / \mathrm{v})$ of a trace metal solution (Vishniac \& Santer, $1957)$ and appropriate carbon and nitrogen sources. Where necessary, media were supplemented with $4 \mu \mathrm{g}$ biotin $\mathrm{l}^{-1}, 1 \mathrm{mg}$ nicotinamide $1^{-1}, 1.4 \mathrm{mg} p$-aminobenzoic acid $1^{-1}, 200 \mathrm{mg}$ histidine $\mathrm{l}^{-1}, 200 \mathrm{mg}$ leucine $\mathrm{l}^{-1}, 365 \mathrm{mg}$ lysine $\mathrm{l}^{-1}$ and $1.22 \mathrm{~g}$ uridine $1^{-1}$. For plate tests, MM was solidified with $1.5 \%$ $(\mathrm{w} / \mathrm{v})$ agar unless stated otherwise. For expression studies, strains were grown for $26 \mathrm{~h}$ on $\mathrm{MM}$ containing $10 \mathrm{mM}$ ammonium tartrate, $0.05 \%(\mathrm{w} / \mathrm{v})$ yeast extract and $2 \%(\mathrm{w} / \mathrm{v})$ sucrose in an orbital shaker at 250 r.p.m. at $30^{\circ} \mathrm{C}$. Mycelium was then harvested, washed with $M M$, transferred to $M M$ containing $10 \mathrm{mM}$ ammonium tartrate and $1 \%(\mathrm{w} / \mathrm{v})$ carbon source as indicated and incubated for another $4 \mathrm{~h}$.

Transformation of $A$. niger, Northern analysis and CHEF analysis. Transformation of $A$. niger was essentially performed as described by Kusters-van Someren et al. (1991) using the A. niger pyrA gene (Goosen et al., 1987) as a selective marker. Plasmid pCRA006 (A. P. MacCabe \& J. Visser, unpublished results) contains the $A$. niger cre $A$ and $p y r A$ genes (the $A$. niger cre $A$ gene was isolated by heterologous hybridization with a probe constructed from $A$. nidulans creA; the identity of the gene was established by comparing the restriction map of the cloned gene with the sequence of A. niger creA published by Drysdale et al., 1993).

For Northern analysis, total RNA was isolated using TRIzol (Life Technologies) according to the manufacturer's instructions. Total RNA ( $20 \mu \mathrm{g}$ for each sample) was run on formaldehyde-containing gels as described by Sambrook $e t$ al. (1989) and transferred onto Hybond-N (Amersham) membranes by capillary blotting in $10 \times$ SSC. Hybridization was done at $42{ }^{\circ} \mathrm{C}$ in buffer containing $50 \%(\mathrm{w} / \mathrm{v})$ formamide, $0.75 \mathrm{M} \mathrm{NaCl}, 50 \mathrm{mM}$ sodium phosphate (pH 7.4), $10 \mathrm{mM}$ EDTA, $2 \times$ Denhardt's, $0 \cdot 1 \%(\mathrm{w} / \mathrm{v})$ SDS and $10 \%(\mathrm{w} / \mathrm{v})$ dextran sulphate. Northern blots were washed at $65^{\circ} \mathrm{C}$ to a final stringency of $0.2 \times \mathrm{SSC} / 0.1 \%(\mathrm{w} / \mathrm{v})$ SDS. Probes were prepared using the random priming method (Sambrook et al., 1989). The following DNA fragments were used as probes: a $1.5 \mathrm{~kb}$ Pst $\mathrm{I}$ fragment from plasmid $\mathrm{pC} 2 \mathrm{X} 1$ (containing the C-terminal region of $a b f A$; Flipphi et al., 1993c); a $1.7 \mathrm{~kb}$ $E c o$ RI-X hoI fragment from plasmid $\mathrm{pB} 2$ (containing the $a b f B$ full-length cDNA; Flipphi et al., 1993a); a 1.1 kb EcoRI-XboI fragment from plasmid pC2N4 (containing the abnA fulllength cDNA; Flipphi et al., 1993b); and a $0.9 \mathrm{~kb}$ EcoRI fragment from plasmid p28S (containing the Agaricus bisporus gene encoding 28S rRNA; Schaap et al., 1996). RNA levels were quantified by laser densitometric scanning of autoradiograms (Ultroscan $\mathrm{XL}, \mathrm{LKB}$ ).

CHEF analysis was performed according to Verdoes et al. (1994) with chromosomal DNA of $A$. niger N402. Hybridization was performed using an $840 \mathrm{bp} X$ hoI-EcoRI fragment of pCRA004 (containing an internal fragment of creA; A.P. MacCabe \& J. Visser, unpublished results) as a probe.

Preparation of cell extracts and enzyme assays. Preparation of cell extracts and assay of L-arabinose reductase and Larabitol dehydrogenase were performed as described by Witteveen et al. (1989). Enzyme assays were performed on a COBAS Bio autoanalyser (Roche) connected to an MS-DOS computer for data logging. Biochemicals were from Boehringer. Protein concentration in extracts was determined as described previously by Witteveen et al. (1989) using the bicinchoninic acid method (Sigma). ABF activity was determined by measuring hydrolysis of $p$-nitrophenyl $\alpha$-Larabinofuranoside (PNP-A; Sigma) as described previously by Van der Veen et al. (1991).

Western blotting. Denaturing electrophoresis in $10 \%(\mathrm{w} / \mathrm{v})$ polyacrylamide gels containing $0 \cdot 1 \%(\mathrm{w} / \mathrm{v})$ SDS was performed as described by Laemmli (1970) in a Mini-V system (Life Technologies). Protein was blotted onto nitrocellulose filters and blots were then incubated with specific antisera, followed by staining with alkaline-phosphatase-labelled goat anti-mouse IgG and alkaline-phosphatase-labelled goat antirabbit IgG as described by the manufacturer (Bio-Rad). Antibodies raised against $A$. niger $\mathrm{ABFA}, \mathrm{ABFB}$ and endoarabinase $A$ have been described previously by Van der Veen et al. (1991).

Polyol extraction and determination. Extraction and determination of intracellular polyols was done as described by Witteveen et al. (1994).

\section{RESULTS}

\section{Isolation and characterization of $A$. niger cre $A^{d}$ mutants}

A. niger cre $A$ mutants were isolated as pseudorevertants of an areA loss-of-function mutation. Following UV- 


\section{Table 1. Growth properties of $A$. niger creA mutants}

Growth characteristics were determined on plates as described in Methods except that nitrate was omitted from the medium; 2.5 mM uridine was added; plates were solidified with agarose; $5 \mathrm{mM} \mathrm{GABA,} \mathrm{L-alanine} \mathrm{or} \mathrm{L-proline} \mathrm{was} \mathrm{used} \mathrm{in} \mathrm{the} \mathrm{presence} \mathrm{and} \mathrm{absence} \mathrm{of}$ $1 \%(w / v)$ D-glucose. Growth score: + , very poor growth; ++ , poor growth; +++ , moderate growth; ++++ , good growth.

\begin{tabular}{|c|c|c|c|c|c|c|c|c|}
\hline \multirow[t]{2}{*}{ Strain } & \multirow{2}{*}{$\begin{array}{l}\text { Relevant } \\
\text { genotype }\end{array}$} & \multirow[t]{2}{*}{ Morphology" } & \multicolumn{6}{|c|}{ Growth on: } \\
\hline & & & GABA & $\begin{array}{l}\text { GABA + D- } \\
\text { glucose }\end{array}$ & L-Proline & $\begin{array}{c}\text { L-Proline + } \\
\text { D-glucose }\end{array}$ & L-Alanine & $\begin{array}{c}\text { L-Alanine }+ \\
\text { D-glucose }\end{array}$ \\
\hline NW141 & are $A 1$ & Normal & + & + & + & + & ++ & + \\
\hline NW142 & are $A 1$ creA1 & Type A & ++ & ++ & + & + & ++ & + \\
\hline NW143 & are $A 1$ cre $A 2$ & Type B & ++ & $+t+t$ & + & ++ & ++ & +++ \\
\hline NW145 & are $A 1$ cre $A 4$ & Type B & ++ & $++t$ & + & ++ & ++ & +++ \\
\hline NW146 & are $A 1$ creA5 & Normal & + & +++ & + & ++++ & ++ & ++ \\
\hline
\end{tabular}

* Morphology classes: normal, white mycelium and good sporulation; type A, yellow mycelium and moderate sporulation; type B, white mycelium and poor sporulation.

mutagenesis of the areA1 strain NW141, strongly growing colonies were selected on MM containing $1 \%$ $(\mathrm{w} / \mathrm{v})$ D-glucose and $1 \%(\mathrm{w} / \mathrm{v})$ GABA. Preliminary growth tests on solid media containing different combinations of carbon and nitrogen sources revealed four putative $c r e A$ mutants which were characterized in more detail. These four mutants were clearly derepressed for using GABA as a nitrogen source in the presence of $D$ glucose (Table 1). Three of the four mutants, creA2, creA4 and creA5, also showed derepression for $\mathrm{L}$-alanine and L-proline utilization. Growth of the parental are $A$ strain NW141 on GABA was very poor and comparable to growth on GABA + D-glucose. The same was observed for L-proline and L-proline $+\mathrm{D}$-glucose. $A$. nidulans are $A$ strains grow rather well on these amino acids, but growth is reduced when D-glucose is added, due to repression by D-glucose of amino acid metabolism (Scazzocchio et al., 1995). For A. niger this is only observed with L-alanine. The explanation for this behaviour is that GABA and L-proline, and to a lesser extent L-alanine, are poor carbon substrates for $A$. niger. In the presence of D-glucose, the amino acids are only required as a nitrogen source, but as D-glucose represses amino acid metabolism, growth is still very poor.

Three classes of morphology were observed (Table 1). creA5 exhibited a normal morphology, i.e. comparable to the parental areA1 strain NW141. creA2, creA4 and to a lesser extent creA1 had difficulty forming conidiospores. The mycelium of creA1 was yellow, unlike the parental strain and the other three mutants, which formed the usual white mycelium.

To test complementation of the mutations with the $A$. niger $c r e A$ gene, the mutants were transformed with plasmid pCRA006, which contains the $A$. niger cre $A$ and pyrA genes (A. P. MacCabe \& J. Visser, unpublished results). For all four mutants, uridine prototrophic strains were obtained. Growth of these transformants on GABA/D-glucose was indistinguishable from the

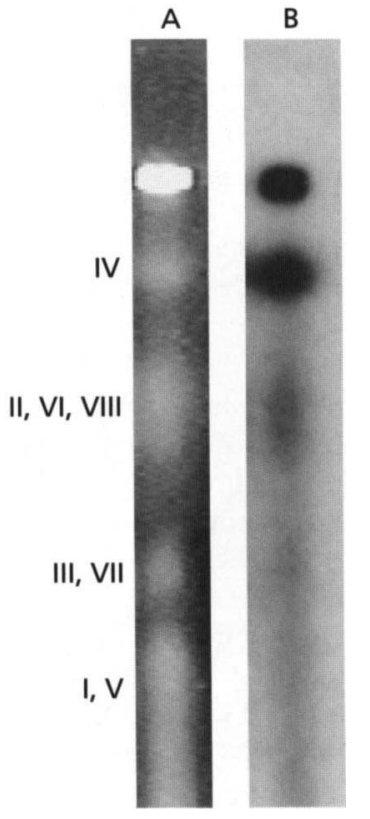

Fig. 1. Chromosome assignment of creA by CHEF analysis. Lane $A$, ethidium-bromide-stained chromosomes of wild-type $A$. niger strain N402 separated by CHEF electrophoresis. Lane B, hybridization of the CHEF blot obtained from the gel shown in lane $A$ with the $840 \mathrm{bp}$ Xhol-EcoRI fragment of creA. Linkage groups of $A$. niger $\mathrm{N402}$ are indicated by Roman numerals on the left.

are $A$ pyr $A^{+}$strain $\mathrm{NW} 140$. In addition, whereas the morphology of creA1, creA2 and creA4 was clearly different from parental strain NW141, their $p y r A^{+} c r e A^{+}$ transformants had reverted to NW140 morphology.

The genetic localization of the creA1 (strain NW142) and creA2 (strain NW143) mutations was determined by linkage analysis. From cross NW142//N616, 58 out of 102 progeny carried areA1 and these were tested for derepression of GABA utilization in the presence of $\mathrm{D}$ - 


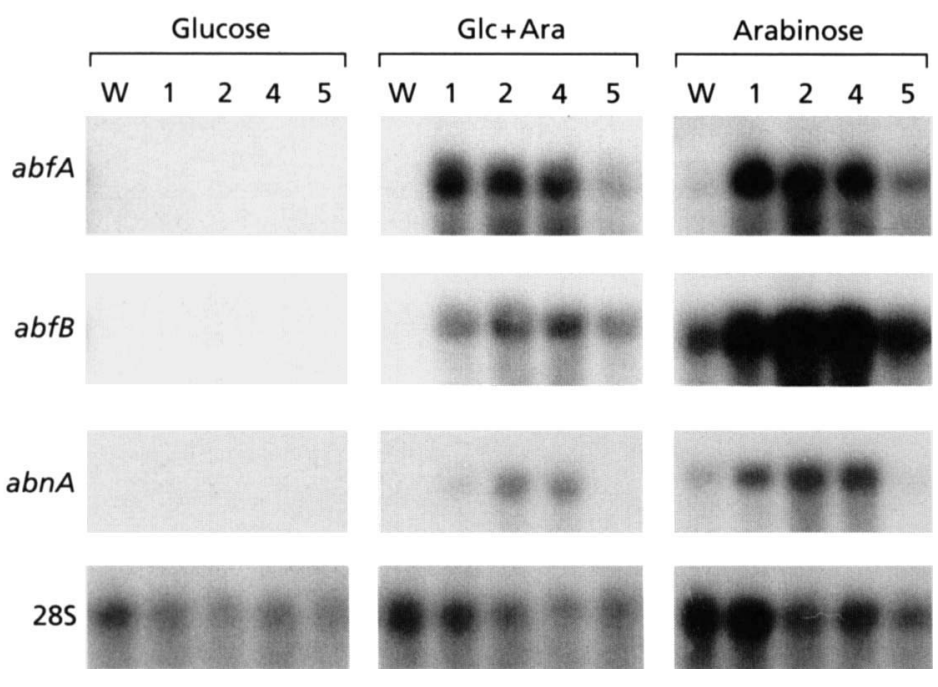

\begin{tabular}{|l|rrrrr|rrrrr|}
\hline & \multicolumn{5}{|c|}{ Glc+Ara } & \multicolumn{5}{c|}{ Arabinose } \\
\cline { 2 - 11 } & $W$ & 1 & 2 & 4 & 5 & W & 1 & 2 & 4 & 5 \\
\cline { 2 - 5 } & 0.0 & 8.8 & 14.9 & 11.9 & 4.2 & 1 & 8.1 & 10.5 & 9.5 & 6.4 \\
$a b f B$ & 0.0 & 0.9 & 1.5 & 2.0 & 1.0 & 1 & 1.3 & 3.1 & 2.6 & 2.1 \\
$a b n A$ & 0.0 & 0.5 & 3.5 & 2.7 & 0.2 & 1 & 2.6 & 5.0 & 4.5 & 0.3 \\
\hline
\end{tabular}

Fig. 2. Arabinase expression in $A$. niger wild-type and creA mutants. Mycelium was grown on sucrose, washed and transferred to D-glucose, D-glucose $+\mathrm{L}$-arabinose (Glc + Ara) or L-arabinose as indicated in the figure. Northern blots were prepared as described in Methods and hybridized separately with $a b f A, a b f B, a b n A$ and $28 S$ probes. RNA levels were quantified by laser densitometric scanning of autoradiograms. The 285 rRNA probe was used as an internal control. In the Table, the amounts of abfA, $a b f B$ and $a b n A$ mRNA relative to 285 rRNA are given for the growth conditions Larabinose and D-glucose $+\mathrm{L}$-arabinose. After growth on D-glucose, transcript levels were insignificant. In addition, for each of the three genes values were normalized to the induced wild-type level (i.e. NW141 grown on L-arabinose) which was set to $1 . W$, Wildtype; 1 , creA1; 2 , creA2; 4, creA4; 5, creA5. glucose. The recombination frequency between creA1 and $l e u A 1$ was $5 \cdot 2 \%$. All other markers gave recombination frequencies between 37 and $54 \%$. Cross NW143//N616 gave comparable results. From a total progeny of 89,33 recombinants contained areA1. Between creA2 and leuA1 $12.1 \%$ recombination was observed, while between $c r e A 2$ and the other markers recombination varied from 38 to $62 \%$. This positioned creA on linkage group IV. Localization of the creA gene on chromosome IV was confirmed by CHEF analysis (Fig. 1).

\section{Effects of creA mutations on expression of ABF and L-arabinose catabolic enzymes}

The possible involvement of CREA in repression by $D$ glucose of arabinases and L-arabinose catabolic enzymes was studied in the creA mutants. Wild-type strain NW141 and creA mutants were grown for $26 \mathrm{~h}$ on MM with $2 \%$ sucrose, and mycelia were subsequently transferred to $1 \%$ L-arabinose, $1 \%$ L-arabinose $+1 \%$ D-glucose and $1 \%$ D-glucose for $4 \mathrm{~h}$. Samples were taken to analyse arabinase transcript levels, arabinase protein levels, activity of arabinases and L-arabinose catabolic enzymes and accumulation of the intermediates of $\mathrm{L}$ arabinose metabolism, L-arabitol and xylitol.

Northern analysis using probes of $a b f A$ (encoding $\mathrm{ABFA}$ ), $a b f B$ (encoding $\mathrm{ABFB}$ ) and $a b n A$ (encoding $A B N A$ ) revealed that upon transfer to $L$-arabinose the wild-type strain expressed all three arabinases (Fig. 2).
Upon transfer of the wild-type strain to D-glucose or Larabinose $+\mathrm{D}$-glucose no expression of the three arabinase genes was detected. In the creA mutants, however, the arabinase genes were clearly expressed on Larabinose $+\mathrm{D}$-glucose. The strongest derepression was observed for mutants $\mathrm{creA} 2$ and $\mathrm{creA} 4$, whereas moderate derepression was observed for creA1 and creA5. On L-arabinose, a higher expression level of the arabinase genes was observed for all four cre $A$ mutants except for $a b n A$ in mutant $c r e A 5$. Again the effect was most pronounced in the case of creA2 and creA4. Relative to the induced wild-type levels, expression of $a b f A$ and $a b n A$ had increased more than $a b f B$.

Arabinase activities were measured in the culture filtrates. During growth on L-arabinose $+\mathrm{D}$-glucose, $\mathrm{ABF}$ activity, measured as PNP-A hydrolysis, was insignificant in a culture filtrate of the wild-type strain, but clearly present in the creA mutants (Fig. 3). ABF activity of mutants creA2 and creA4 even approached the induced wild-type level (i.e. comparable to NW141 grown on L-arabinose). On L-arabinose, $\mathrm{ABF}$ activity in creA2, creA4 and creA5 was 1.6-, 2.5- and 2.1-fold the wild-type level, respectively, whereas creA1 was comparable to wild-type. ABNA activity remained too low to be accurately measured.

Immunochemical detection of the arabinase proteins by Western blotting qualitatively corroborated the results of the Northern analysis and the activity measurements (data not shown) and confirmed that of the two ABFs 


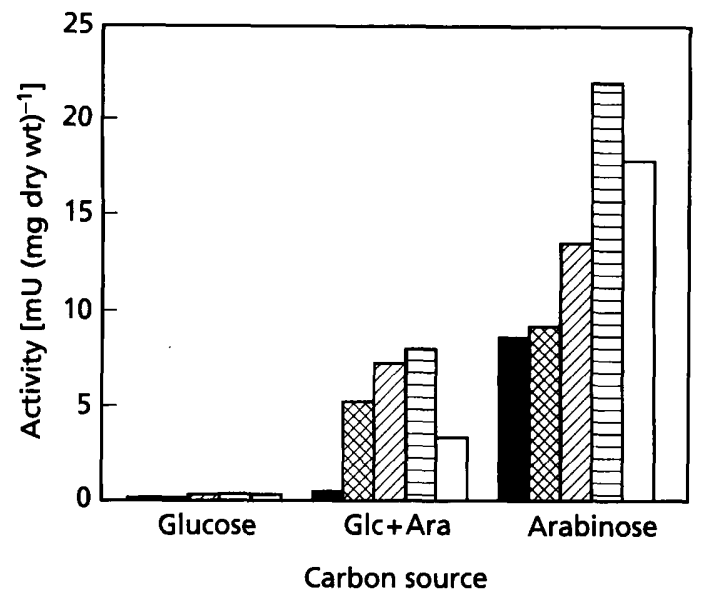

Fig. 3. $A B F$ activity in culture filtrates of $A$. niger wild-type and creA mutants. Growth was as described in the legend of Fig. 2. ABF activity was determined by measuring hydrolysis of PNP-A. Activities are expressed as $\mathrm{mU}\left(\mathrm{mg}\right.$ dry $\mathrm{wt}^{-1}$ [equivalent to $\mathrm{nmol}$ PNP produced $\mathrm{min}^{-1}$ (mg dry $\mathrm{wt}^{-1}$ ). Data are the mean of two experiments. $\square$, Wild-type; $\otimes$, creA1; $\square$, creA2; 目, creA4; $\square$, creA5. GlC +Ara, D-glucose + L-arabinose.

present in wild-type $A$. niger ( $\mathrm{ABFA}$ and $\mathrm{ABFB}$ ), $\mathrm{ABFB}$ is the main activity (Van der Veen et al., 1993). ABNA was not detected. Both ABFA and ABFB were clearly derepressed in the creA mutants grown on L-arabinose + D-glucose. On L-arabinose, the quantity of ABFB produced by the creA mutants was apparently comparable to that observed for the wild-type strain, but the ABFA levels of the creA mutants were higher than that of the wild-type. However, it should be remembered that Western blot analysis does not provide quantitative data.

Activities of the enzymes involved in catabolism of Larabinose ( $\mathrm{L}$-arabinose reductase, $\mathrm{L}$-arabitol dehydrogenase, L-xylulose reductase and xylitol dehydrogenase) were analysed in parallel. For all strains the activities of $\mathrm{L}$-arabinose reductase and $\mathrm{L}$-arabitol dehydrogenase were low during growth on D-glucose (Fig. 4). On Dglucose $+\mathrm{L}$-arabinose, the $\mathrm{L}$-arabinose reductase and $\mathrm{L}$ arabitol dehydrogenase activities were still low in wildtype strain NW141, but were increased in the creA mutants. Similar results were obtained for L-xylulose reductase and xylitol dehydrogenase (data not shown). Derepression was most pronounced in the case of Larabitol dehydrogenase, its activity in creA1 and creA4 being approximately fourfold the wild-type activity. In contrast to the results obtained for arabinases where creA2 and creA4 were most strongly derepressed, creA1 and creA4 were derepressed most for the L-arabinose catabolic enzymes. During growth on L-arabinose, the activities of $\mathrm{L}$-arabinose reductase and $\mathrm{L}$-arabitol dehydrogenase were up to twofold higher in the creA mutants than in wild-type strain NW141.

Derepression of the L-arabinose catabolic enzymes during growth on a combination of D-glucose and L-

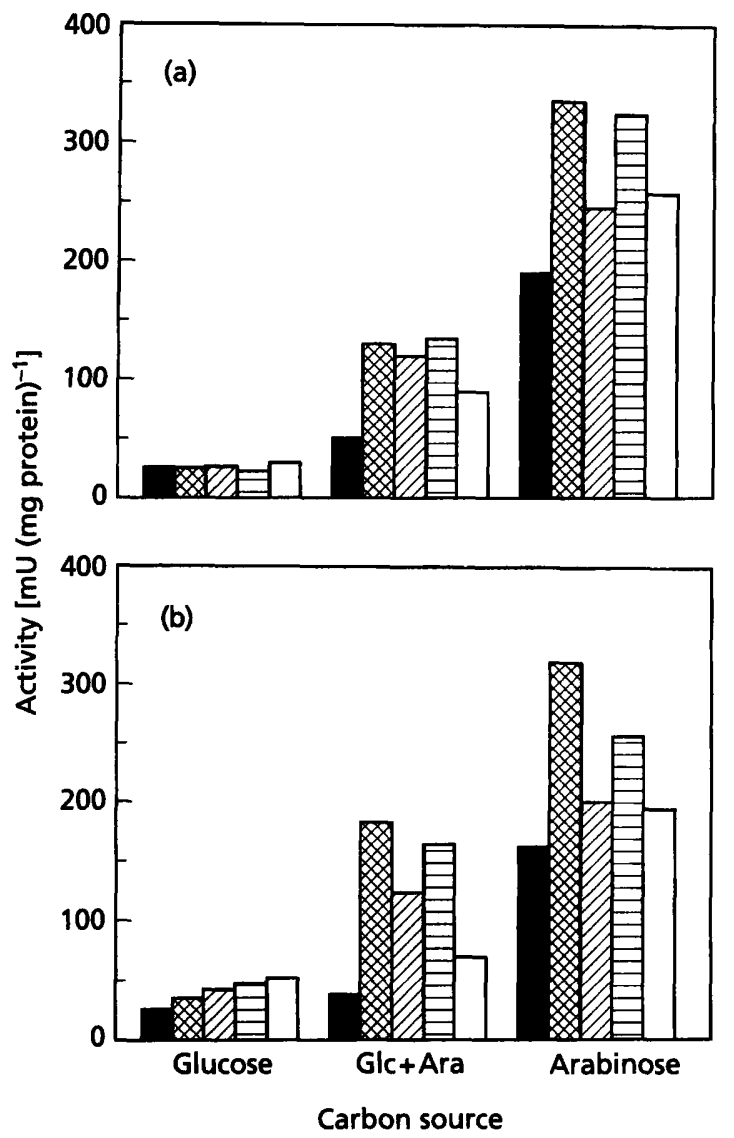

Fig. 4. Specific activity of L-arabinose reductase (a) and Larabitol dehydrogenase (b) in cell extracts of $A$. niger wild-type and creA mutants. Mycelium was cultured as described in the legend of Fig. 2. Activities were measured as described in Methods. Data are the mean of two experiments. $\square$, Wild-type; 四，creA1; 2 , creA2; 目，creA4; $\square, c r e A 5$. Glc+Ara， Dglucose + L-arabinose.

arabinose might result in intracellular accumulation of the polyol compounds xylitol and L-arabitol, which are intermediates in $\mathrm{L}$-arabinose degradation (Witteveen $e t$ al., 1989). L-Arabitol levels cannot be determined unequivocally due to simultaneous formation of $\mathrm{D}$ arabitol from the pentose phosphate pathway intermediate D-xylulose 5-phosphate under all conditions and the inability to distinguish between $\mathrm{D}$ - and $\mathrm{L}$ arabitol by HPLC analysis. The appearance of xylitol, however, is diagnostic of the presence of $\mathrm{L}$-arabitol. No xylitol was observed in any of the strains during growth on D-glucose, whereas a considerable amount of xylitol accumulated during growth on L-arabinose (Table 2). On D-glucose + L-arabinose, a very low level of xylitol was observed in the wild-type strain, but xylitol did accumulate in the creA mutants, indicative of derepression of L-arabinose catabolism. As expected, arabitol was found under all growth conditions, but the levels were relatively high during growth on L-arabinose, implying accumulation of L-arabitol. 
Table 2. Intracellular polyol concentrations in $A$. niger wild-type and creA mutants during growth on D-glucose, D-glucose + L-arabinose and L-arabinose

Polyol concentrations are expressed in $\mu \mathrm{mol}(\mathrm{g} \text { dry wt })^{-1}$. Data are the mean of two experiments.

\begin{tabular}{|c|c|c|c|c|c|c|c|}
\hline \multirow[t]{2}{*}{ Strain } & \multirow{2}{*}{$\begin{array}{l}\text { Relevant } \\
\text { genotype }\end{array}$} & \multicolumn{2}{|c|}{ D-Glucose } & \multicolumn{2}{|c|}{ D-Glucose + L-arabinose } & \multicolumn{2}{|c|}{ L-Arabinose } \\
\hline & & Xylitol & Arabitol & Xylitol & Arabitol & Xylitol & Arabitol \\
\hline NW141 & Wild-type & 0 & 16 & 1 & 19 & 25 & 106 \\
\hline NW142 & creA1 & 0 & 7 & 19 & 25 & 30 & 100 \\
\hline NW143 & creA2 & 0 & 40 & 13 & 59 & 56 & 136 \\
\hline NW145 & creA4 & 0 & 38 & 14 & 58 & 66 & 154 \\
\hline NW146 & creAs & 0 & 14 & 6 & 26 & 23 & 93 \\
\hline
\end{tabular}

\section{DISCUSSION}

Hyphal fungi seem to share the regulatory system responsible for carbon repression which was first described for $A$. nidulans on the basis of mutations in creA (Arst \& Cove, 1973; Bailey \& Arst, 1975; Hynes \& Kelly, 1977) and further substantiated by the cloning of this gene (Dowzer \& Kelly, 1989, 1991). The A. niger creA gene was found to be very similar to the A. nidulans creA gene and, moreover, was shown to be functional in A. nidulans (Drysdale et al., 1993). However, thus far no creA mutants have been described for $A$. niger. In this report, we describe such mutants which have, as expected, a derepressed phenotype. The following results imply that the mutants we isolated are impaired in creA. The mutants were derepressed for a number of systems involved in carbon catabolism. In an are $A$ background, the cre $A$ mutations allowed utilization of GABA, L-proline or L-alanine as nitrogen sources in the presence of $\mathrm{D}$-glucose (Table 1). Whereas the parent showed repression of arabinases and $\mathrm{L}$-arabinose catabolism in medium containing both L-arabinose and $D$-glucose, these functions were clearly derepressed in the creA mutants under the same conditions (Figs 2-4). Finally, transformation of the mutant strains with the $A$. niger cre $A$ gene resulted in a phenotype that was indistinguishable from the parental are $A$ strain. The finding that the $A$. niger cre $A$ gene was able to complement the mutations is a strong indication that we have isolated creA mutants.

The different $A$. niger cre $A$ alleles also displayed nonhierarchical heterogeneity, observed with A. nidulans creA mutants as well (Arst \& Bailey, 1977) and indicative of a direct effect of CREA on transcription. For example, whereas creA2 and creA4 were strongly derepressed for the use of GABA and L-alanine in the presence of D-glucose and less for L-proline, creA5 showed exactly the opposite phenotype.

A. niger creA mutants further exhibited decreased growth rates and reduced sporulation. In addition, $A$. niger creA1 produced a yellow pigment, which is probably a secondary metabolite whose biosynthesis is normally repressed by D-glucose.
From our results it appears that $c r e A 2$ and $c r e A 4$ are the most interesting alleles. These alleles are extremely useful for investigating the involvement of CREA in the control of other systems subject to carbon repression. Cloning and sequencing of the creA alleles may be useful for identifying domains in the protein, other than the zinc finger region, that are important for its function. This was recently done by Shroff et al. (1996) for a number of $A$. nidulans cre $A$ alleles. Three of the $A$. nidulans cre $A$ alleles analysed have missense mutations in the zinc finger domain whereas four other mutations result in truncations of CREA between the zinc finger domain and the C-terminus of the protein.

Analysis of arabinase expression in A. nidulans cre A mutants has demonstrated that the arabinase system is suitable for investigating carbon repression in this fungus (Van der Veen et al., 1994). The A. niger arabinases (ABFA, ABFB and ABNA) are induced by Larabinose and L-arabitol, whereas addition of D-glucose prevents this induction (Van der Veen et al., 1993; Flipphi et al., 1994). Similarly, enzymes involved in catabolism of L-arabinose are expressed during growth on L-arabinose, but not on D-glucose (Witteveen et al., 1989). These observations suggest repression of arabinases and L-arabinose catabolic enzymes by D-glucose. In this report, we show that this repression is in fact mediated by CREA. No expression of $a b f A, a b f B$ and $a b n A$ was detected on a combination of $\mathrm{L}$-arabinose $+\mathrm{D}$ glucose in the wild-type strain. In the creA mutants, however, the three arabinase genes were clearly expressed under these conditions (Fig. 2). Biosynthesis and secretion of the arabinases was confirmed by Western blot analysis and activity in the case of ABFA and ABFB, but not for ABNA (Fig. 3). The absence of ABNA is explained by the delayed expression of $a b n A$ compared to $a b f A$ and $a b f B$, which has been observed previously by Flipphi et al. (1994). L-Arabinose reductase and Larabitol dehydrogenase, the enzymes involved in Larabinose catabolism, were also derepressed in the creA mutants (Fig. 4). Several putative CREA-binding sites are present in the promoters of the three arabinaseencoding genes (Flipphi et al., 1994) and it is most likely that CREA directly represses the genes encoding arabi- 
nases and L-arabinose catabolic enzymes by binding to its cognate sequence(s) in the promoters of these genes. This is substantiated by the non-hierarchical heterogeneity amongst the different $c r e A$ alleles. Thus, while cre $A 2$ and $c r e A 4$ showed stronger derepression of $a b n A$ than of $a b f B$, derepression of $a b n A$ was much less than that of $a b f B$ in creA5. Similarly, derepression of arabinase genes was more pronounced for creA2 and creA4 than for $c r e A 1$, but $c r e A 1$ was more derepressed for $L-$ arabinose reductase and $\mathrm{L}$-arabitol dehydrogenase. Two other possible mechanisms of repression of genes encoding arabinases and L-arabinose catabolic enzymes are (1) a cascade mechanism, i.e. repression of a common transcription activator protein and (2) lack of inducer formation. A common transcription activator for arabinases has been proposed by Flipphi et al. (1994) on the basis of the finding that extra gene copies of either $a b f A$ or $a b f B$ decreased expression of the other $a b f$ gene and, more obviously, of the more weakly expressed $a b n A$ gene. A cascade mechanism for repression operates in the case of the alc system in $A$. nidulans. The gene encoding the transcription activator of the alc system, alcR, is repressed by D-glucose, partially preventing induction of the alc system (Kulmburg et al., 1993). However, most of the alc genes, including alcA which is the structural gene for alcohol dehydrogenase I, are also repressed directly by CREA (Fillinger \& Felenbok, 1996; Kulmburg et al., 1993). The second alternative for direct repression is lack of inducer formation. Arabinases are induced by L-arabitol, an intermediate of L-arabinose metabolism (Van der Veen et al., 1993), and derepression of $\mathrm{L}$-arabinose uptake and $\mathrm{L}$-arabinose reductase, which could result in intracellular accumulation of L-arabitol, might be sufficient to induce expression of arabinases. Such a mechanism operates, for example, in the case of the GAL genes in S. cerevisiae, where MIG1 represses the expression of the D-galactose permease thereby reducing the level of functional inducer (Johnston $e t$ al., 1994). Proper investigation of the relative contribution of the three repression mechanisms mentioned requires isolation of the genes encoding the putative arabinase transcription activator, the L-arabinose permease and the enzymes involved in L-arabinose catabolism.

\section{ACKNOWLEDGEMENTS}

The work described in this paper was financially supported in part by the Ministry of Economic Affairs, the Ministry of Education, Culture and Science, The Ministry of Agriculture, Nature Management and Fishery in the framework of an industrial relevant research programme of the Netherlands Association of Biotechnology Centres (ABON) and in part by the European Community (to J.V.; grant B102-CT93-0174) for research on wide-domain regulation.

\section{REFERENCES}

Arst, H. N., Jr \& Bailey, C. R. (1977). The regulation of carbon metabolism in Aspergillus nidulans. In Genetics and Physiology of Aspergillus nidulans, pp. 131-146. Edited by J. E. Smith \& J. A. Pateman. London: Academic Press.

Arst, H. N., Jr \& Cove, D. J. (1973). Nitrogen metabolite repression in Aspergillus nidulans. Mol Gen Genet 126, 111-141.
Arst, H. N., Jr \& MacDonald, D. W. (1975). A gene cluster in Aspergillus nidulans with an internally located cis-acting regulatory region. Nature 254, 26-31.

Bailey, C. R. \& Arst, H. N., Jr (1975). Carbon catabolite repression in Aspergillus nidulans. Eur J Biochem 51, 573-577.

Bos, C. J., Debets, A. J. M., Swart, K., Huybers, A., Kobus, G. \& Slakhorst, S. M. (1988). Genetic analysis and the construction of master strains for assignment of genes to six linkage groups in Aspergillus niger. Curr Genet 14, 437-443.

Cubero, B. \& Scazzocchio, C. (1994). Two different, adjacent and divergent zinc finger binding sites are necessary for CREAmediated carbon catabolite repression in the proline gene cluster of Aspergillus nidulans. EMBO J 13, 407-415.

Dowzer, C. E. A. \& Kelly, J. M. (1989). Cloning of creA from Aspergillus nidulans: a gene involved in carbon catabolite repression. Curr Genet 15, 457-459.

Dowzer, C. E. A. \& Kelly, J. M. (1991). Analysis of the creA gene, a regulator of carbon catabolite repression in Aspergillus nidulans. Mol Cell Biol 11, 5701-5709.

Drysdale, M. R., Kolze, S. E. \& Kelly, J. M. (1993). The Aspergillus niger carbon catabolite repressor gene, creA. Gene 130, 241-245. Fillinger, S. \& Felenbok, B. (1996). A newly identified gene cluster in Aspergillus nidulans comprises five novel genes localized in the alc region that are controlled both by the specific transactivator AlcR and the general carbon-catabolite repressor CreA. Mol Microbiol 20, 475-488.

Flipphi, M. J. A., van Heuvel, M., Van der Veen, P., Visser, J. \& de Graaff, L. H. (1993a). Cloning and characterization of the $a b f B$ gene coding for the major $\alpha$-L-arabinofuranosidase (ABF B) of Aspergillus niger. Curr Genet 24, 525-532.

Flipphi, M. J. A., Panneman, H., Van der Veen, P., Visser, J. \& de Graaff, L. H. (1993b). Molecular cloning, expression and structure of the endo-1,5- $\alpha-\mathrm{L}$-arabinase gene of Aspergillus niger. Appl Microbiol Biotechnol 40, 318-326.

Flipphi, M. J. A., Visser, J., Van der Veen, P. \& de Graaff, L. H. (1993c). Cloning of the Aspergillus niger gene encoding $\alpha-\mathrm{L}-$ arabinofuranosidase A. Appl Microbiol Biotechnol 39, 335-340.

Flipphi, M. J. A., Visser, J., Van der Veen, P. \& de Graaff, L. H. (1994). Arabinase gene expression in Aspergillus niger: indications for coordinated regulation. Microbiology 140, 2673-2682.

Goosen, T., Bloemheuvel, G., Gysler, C., de Bie, D. A., Van den Broek, H. W. J. \& Swart, K. (1987). Transformation of Aspergillus niger using the homologous orotidine- 5 -phosphate-decarboxylase gene. Curr Genet 11, 499-503.

Hynes, M. J. \& Kelly, J. M. (1977). Pleiotropic mutants of Aspergillus nidulans altered in carbon metabolism. Mol Gen Genet 150, 193-204.

Johnston, M., Flick, J. S. \& Pexton, T. (1994). Multiple mechanisms provide rapid and stringent glucose repression of gal gene expression in Saccharomyces cerevisiae. Mol Cell Biol 14, 3834-3841.

Kelly, J. M. (1994). Carbon catabolite repression. Prog Ind Microbiol 29, 355-367.

Kulmburg, P., Mathieu, M., Dowzer, C., Kelly, J. \& Felenbok, B. (1993). Specific binding sites in the alcR and alcA promoters of the ethanol regulon for the CREA repressor mediating carbon catabolite repression in Aspergillus nidulans. Mol Microbiol 7, 847-857.

Kusters-van Someren, M. A., Harmsen, J. A. M., Kester, H. C. M. \& Visser, J. (1991). Structure of the Aspergillus niger pelA gene and its expression in Aspergillus niger and Aspergillus nidulans. Curr Genet 20, 293-299. 
Laemmli, U. K. (1970). Cleavage of structural proteins during the assembly of the head of bacteriophage T4. Nature 227, 680-685.

Nehlin, J. O. \& Ronne, H. (1990). Yeast MIG1 repressor is related to the mammalian early growth response and Wilms' tumour finger proteins. $E M B O J \mathbf{9}, 2891-2898$.

Nehlin, J. O., Carlberg, M. \& Ronne, H. (1991). Control of yeast GAL genes by MIG1 repressor: a transcriptional cascade in the glucose response. EMBO J 10, 3373-3377.

Pontecorvo, G., Roper, J. A., Hemmons, L. M., MacDonald, K. D. \& Bufton, A. W. J. (1953). The genetics of Aspergillus nidulans. Adv Genet 5, 141-238.

Ruijter, G. J. G. \& Visser, J. (1997). Carbon repression in Aspergilli. FEMS Microbiol Lett 151, 103-114.

Sambrook, J., Fritsch, E. F. \& Maniatis, T. (1989). Molecular Cloning: a Laboratory Manual, 2nd edn. Cold Spring Harbor, NY: Cold Spring Harbor Laboratory.

Scazzocchio, C., Gavrias, V., Cubero, B., Panozzo, C., Mathieu, M. \& Felenbok, B. (1995). Carbon catabolite repression in Aspergillus nidulans: a review. Can J Bot 73, S160-S166.

Schaap, P. J., Múller, Y., Baars, J. J. P., Op den Camp, H. J. M., Sonnenberg, A. S. M., Van Griensven, L. J. L. D. \& Visser, J. (1996). Nucleotide sequence and expression of the gene encoding $\mathrm{NADP}^{+}$-dependent glutamate dehydrogenase ( $\left.g d h \mathrm{~A}\right)$ from Agaricus bisporus. Mol Gen Genet 250, 339-347.

Shroff, R. A., Lockington, R. A. \& Kelly, J. M. (1996). Analysis of mutations in the creA gene involved in carbon catabolite repression in Aspergillus nidulans. Can J Microbiol 42, 950-959.
Van der Veen, P., Flipphi, M. J. A., Voragen, A. G. J. \& Visser, J. (1991). Induction, purification and characterisation of arabinases produced by Aspergillus niger. Arch Microbiol 157, 23-28.

Van der Veen, P., Flipphi, M. J. A., Voragen, A. G. J. \& Visser, J. (1993). Induction of extracellular arabinases on monomeric substrates in Aspergillus niger. Arch Microbiol 159, 66-71.

Van der Veen, P., Arst, H. N., Jr, Flipphi, M. J. A. \& Visser, J. (1994). Extracellular arabinases in Aspergillus nidulans: the effect of different cre mutations on enzyme levels. Arch Microbiol 162, 433-440.

Verdoes, J. C., Calil, M. R., Punt, P. J., Debets, F., Swart, K., Stouthamer, A. H. \& Van den Hondel, C. A. J. J. (1994). The complete karyotype of Aspergillus niger: the use of introduced electrophoretic mobility variation of chromosomes for gene assignment studies. Mol Gen Genet 244, 75-80.

Vishniac, W. \& Santer, M. (1957). The thiobacilli. Bacteriol Rev 21, 195-213.

Witteveen, C. F. B., Busink, R., Van de Vondervoort, P. J. I., Dijkema, C., Swart, K. \& Visser, J. (1989). L-Arabinose and Dxylose catabolism in Aspergillus niger. J Gen Microbiol 135, 2163-2171.

Witteveen, C. F. B., Weber, F., Busink, R. \& Visser, J. (1994). Isolation and characterisation of two xylitol dehydrogenases from Aspergillus niger. Microbiology 140, 1679-1685.

Received 22 April 1997; accepted 6 June 1997. 